\title{
DIAGNÓSTICO FÍSICO-QUÍMICO DA ÁGUA DE BEBEDOUROS NAS ESCOLAS PÚBLICAS DA CIDADE DE ESPERANÇA/PB
}

Physical-chemical diagnosis of water from drinking fountains in the public schools

of the city of Esperança/PB

Diagnóstico físico-químico del agua de los bebederos en las escuelas públicas de la ciudad de Esperança/PB

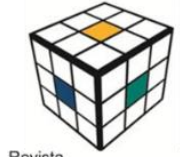

Desafios

Artigo Original

Original Article

Artículo Original

Aldeni Barbosa da Silva ${ }^{*}$, Josikleio da Costa Silva ${ }^{1}$, Bianca Feliciano de Melo ${ }^{1}$, Rodrigo Félix do Nascimento ${ }^{1}$, Jonatas da Silva Duarte ${ }^{2}$, Edmilson Dantas da Silva Filho ${ }^{2}$

${ }^{1}$ Instituto Federal de Educação, Ciência e Tecnologia da Paraíba, Campus Esperança, Brasil.

${ }^{2}$ Instituto Federal de Educação, Ciência e Tecnologia da Paraíba, Campus Campina Grande, Brasil.

* Correspondência: Instituto Federal de Educação, Ciência e Tecnologia da Paraíba, Campus Esperança. Rua Joaquim Virgulino da Silva, S/N - Centro, Esperança-PB. CEP: 58135-000. E-mail: aldeni.silva@ifpb.edu.br

\section{RESUMO}

Objetivou-se com esse trabalho verificar os parâmetros físico-químicos da água dos bebedouros das escolas municipais da zona urbana da cidade de Esperança-PB. As amostras foram coletadas em garrafas plásticas de 2 litros e foram encaminhadas ao Laboratório do Programa de Pesquisa em Saneamento Básico (PROSAB), em Campina Grande-PB, para a realização das análises. Os valores foram avaliados conforme as recomendações da portaria de consolidação $\mathrm{N}^{\circ}$ 05/2017. Os parâmetros analisados foram: $\mathrm{pH}$, temperatura, cor aparente, condutividade elétrica, turbidez, alcalinidade, dureza total, cloreto, nitrito, nitrato, sólidos totais dissolvidos, sólidos totais voláteis e sólidos totais fixos. Com relação ao pH todas as amostras atenderam aos padrões estipulados; com relação a cor aparente, todas as amostras estão em desacordo com as normas vigentes; a condutividade elétrica das águas resultou numa média de 380,6 $\mu \mathrm{S} / \mathrm{Cm}$; a alcalinidade média foi de 79,18 mg/L de $\mathrm{CaCO}_{3}$; as amostras apresentaram dureza branda; o teor de cloreto, nitrito e nitrato estão dentro dos padrões permitidos; as amostras apresentaram turbidez que variou de 0 a 0,33, corroborando com as normas; com relação aos Sólidos Totais Dissolvidos, voláteis e fixos, os valores variaram de 94 a $302 \mathrm{mg} \mathrm{L}^{-1}, 4$ a $258 \mathrm{mg} \mathrm{L}^{-1}$ e 4 a $280 \mathrm{mg} \mathrm{L}^{-1}$, respectivamente.

Palavras-chave: Qualidade da água, Água Potável, Saúde Pública.

\section{ABSTRACT}

The objective of this study was to verify the physical-chemical parameters of drinking water from municipal schools in the urban area of the city of Esperança-PB. The samples were collected in 2 liter plastic bottles and sent to the Laboratory of the Basic Sanitation Research Program (PROSAB), in Campina Grande-PB, for the analysis. The 
amounts were evaluated according to the recommendations of consolidation order No 05/2017. The parameters analyzed were: pH, temperature, apparent color, electrical conductivity, turbidity, alkalinity, total hardness, chloride, nitrite, nitrate, total dissolved solids, total volatile solids and total fixed solids. With regard to $\mathrm{pH}$, all samples met the stipulated standards; with respect to apparent color, all samples are in disagreement with the current norms; the electrical conductivity of the waters resulted in an average of $380.6 \mu \mathrm{S} / \mathrm{Cm}$; the mean alkalinity was $79.18 \mathrm{mg} / \mathrm{L} \mathrm{CaCO}_{3}$; the samples presented soft hardness; the content of chloride, nitrite and nitrate are within the permitted standards; the samples showed turbidity ranging from 0 to 0.33, corroborating with the norms; in relation to total dissolved solids, volatile and fixed, the values ranged from 94 to $302 \mathrm{mg} \mathrm{L}^{-1}, 4$ to $258 \mathrm{mg} \mathrm{L}^{-1}$ and 4 to $280 \mathrm{mg} \mathrm{L}^{-1}$, respectively.

Keywords: Water quality, Potable Water, Public Health

\section{RESUMEN}

Se objetivó con ese trabajo verificar los parámetros físico-químicos del agua de los bebederos de las escuelas municipales de la zona urbana de la ciudad de Esperanza-PB. Las muestras fueron recolectadas en botellas plásticas de 2 litros y fueron encaminadas al Laboratorio del Programa de Investigación en Saneamiento Básico (PROSAB), en Campina Grande-PB, para la realización de los análisis. Los valores fueron evaluados conforme a las recomendaciones de la orden de consolidación No 05/2017. Los parámetros analizados fueron: pH, temperatura, color aparente, conductividad eléctrica, turbidez, alcalinidad, dureza total, cloruro, nitrito, nitrato, sólidos totales disueltos, sólidos totales volátiles y sólidos totales fijos. Con respecto al pH todas las muestras atendieron a los estándares estipulados; con respecto al color aparente, todas las muestras están en desacuerdo con las normas vigentes; la conductividad eléctrica de las aguas resultó en una media de 380,6 $\mu \mathrm{S} / \mathrm{Cm}$; la alcalinidad media fue de 79,18 mg/L de $\mathrm{CaCO}_{3}$; las muestras presentaron dureza blanda; el contenido de cloruro, nitrito y nitrato están dentro de los estándares permitidos; las muestras presentaron turbidez que varió de 0 a 0,33, corroborando con las normas; en cuanto a los Sólidos Totales Disueltos, volátiles y fijos, los valores variaron de 94 a $302 \mathrm{mg} \mathrm{L}^{-1}$, 4 a $258 \mathrm{mg} \mathrm{L}^{-1}$ y 4 a $280 \mathrm{mg} \mathrm{L}^{-1}$, respectivamente.

Decriptores: Calidad del agua, Agua potable, Salud pública.

\section{INTRODUÇÃO}

A água é o constituinte inorgânico mais abundante na matéria viva, integrando aproximadamente dois terço do corpo humano e atingindo até $98 \%$ para certos animais aquáticos, legumes, frutas e verduras. Constitui-se também no solvente universal da maioria das substâncias, modificando-as e modificando-se em função destas (LIBÂNIO, 2010).

É uma substância essencial para todos os seres vivos e em todos os estágios da vida é considerado um recurso insubstituível. Apesar de sua importância, a oferta hídrica para abastecimento tem denotado um dos grandes problemas de saúde pública do século XXI (PORTO et al., 2011). Embora seja considerada uma das substâncias mais presentes na natureza, é imprescindível que haja determinados cuidados no tocante à quantidade de uso, qualidade e distribuição da água (BEAL et al., 2014; ALVES et al., 2018).

Devido à abundância deste elemento líquido é possível ter uma falsa impressão de que se trata de um recurso inesgotável (Porto et al., 2011), quando na verdade, a realidade que temos atualmente é de que apenas $2,5 \%$ de toda água do planeta terra é constituída por água doce (Ribeiro; Rolim, 2017), e a grande parte das águas doces do planeta está armazenada sob a forma de geleiras que aprisionam 
nada menos do que $68,7 \%$ de toda a água doce disponível. Outra parte considerável $(30,9 \%)$ das águas doces está nos aquíferos e nos solos congelados das florestas boreais (permafrost) (PINTO-COELHO; HAVENS, 2016; SILVA et al., 2018).

As caracterizações físico-químicas da água e de soluções aquosas têm como objetivo identificar e quantificar os elementos e espécies iônicas presentes nesses compostos e associar os efeitos de suas propriedades às questões ambientais, permitindo a compreensão dos processos naturais ou alterações no meio ambiente. $\mathrm{O}$ conhecimento das propriedades físicas e químicas de átomos e moléculas, e de suas interações, permitem responder a questões como, quais e em que níveis eles podem ser adversos aos ecossistemas e à saúde humana. Os teores determinados nas amostras analisadas são comparados aos padrões conhecidos, os quais são especificados em portarias e resoluções legais, que dão subsídios aos laboratórios na expedição de seus laudos (PARRON et al., 2011).

No Brasil, as legislações vigentes que tratam de potabilidade da água para consumo humano são, respectivamente, a portaria de consolidação de $\mathrm{n}^{\circ} 5$, de 28 de setembro de 2017, do Ministério da Saúde (BRASIL, 2017) e a resolução ${ }^{\circ}$ 396, de 3 de abril de 2008, do Conselho Nacional do Meio Ambiente (BRASIL, 2008).

De acordo com a definição da portaria n. $^{\circ}$ 2914/2011 do Ministério da Saúde, no Art. 4º água potável é a água para consumo humano cujos parâmetros microbiológicos, físicos, químicos e radioativos atendam ao padrão de potabilidade e que não ofereça riscos à saúde.

As escolas são locais onde as crianças e adolescentes passam grande parte de seu tempo durante o dia, com pelo menos 200 dias letivos anuais. Esta permanência na escola determina que seja ingerido relevantes quantidades de água. Por isso, a água distribuída nos estabelecimentos escolares obrigatoriamente deve ter qualidade potável de acordo com o preconizado pelo Ministério da Saúde. Sabe-se que a precarização da educação é um fato ordinário no país, com escolas inadequadas desde a construção das salas até o armazenamento e distribuição da água para o consumo. (TRINDADE et al., 2015).

Diante disso, esse trabalho teve como objetivo verificar os parâmetros físico-químicos da água dos bebedouros das escolas municipais da zona urbana da cidade de Esperança - PB.

\section{MATERIAIS E MÉTODOS}

\section{Área de Estudo}

O estudo foi desenvolvido em cinco escolas municipais de Esperança no estado da Paraíba, localizada na mesorregião do Agreste Paraibano, situada entre as coordenadas geográficas de 0701'59”' S e 3551'26” W, com altitude média de 630 metros, e uma área territorial de $161,138 \mathrm{~km}^{2}$, apresentando uma população estimada em 33.003 habitantes, e densidade demográfica de 189,86 $\mathrm{hab} / \mathrm{km}^{2}$ (IBGE, 2018). Essa cidade fica aproximadamente a $146 \mathrm{~km}$ da capital João Pessoa e a $25 \mathrm{~km}$ de Campina Grande, cidade na qual se mantém maiores vínculos comerciais.

\section{Amostras para análises físico-químicas}

As amostras de água destinadas para as análises físico-químicas foram coletadas em garrafas plásticas de 2 litros diretamente dos bebedouros e foram encaminhadas ao Laboratório do Programa de 
Pesquisa em Saneamento Básico (PROSAB), em Campina Grande, para a realização das análises.

Os parâmetros físico-químicos das águas foram determinados seguindo-se as metodologias do manual do Standard Methods - For the Examination of Water and Wastewater (APHA, 2012). Os valores foram avaliados conforme as recomendações da portaria de consolidação No 05/2017 do Ministério da Saúde (BRASIL, 2017).

Por motivos éticos, o nome das referidas escolas foram mantidos em sigilo, sendo as amostras coletadas nas mesmas, identificadas como amostras 1, 2, 3, 4 e 5. Os parâmetros analisados e os métodos de análises foram os seguintes:

\section{pH}

A medida do $\mathrm{pH}$ baseou-se na determinação da atividade dos íons hidrogênio. $\mathrm{O}$ pH foi determinado pelo método potenciométrico, com o pHmetro de bancada microporcessado da marca Tecnal, modelo TEC-11, previamente calibrado com soluções-tampão de pH 7,0 e de $\mathrm{pH}$ 4,0, com resultados expressos em escala logarítmica de $\mathrm{pH}$.

\section{Temperatura}

A temperatura da água foi determinada com o uso de termômetro digital comum, modelo HANNA Hl 98501-1, com uma casa decimal de precisão, na escala de ${ }^{\circ} \mathrm{C}$.

\section{Turbidez}

A medida da turbidez baseou-se na medida do grau de interferência à passagem de luz através da água. A turbidez foi determinada pelo método nefelométrico, com um turbidímetro da marca Tecnal, modelo TB-1000 / MS Tecnopon.

\section{Alcalinidade}

A alcalinidade total é a sua capacidade de neutralização de ácidos e equivale à soma de todas as bases tituláveis. A alcalinidade foi determinada pelo método da Titulação Potenciométrica, que baseia-se na titulação de um determinado volume da amostra com solução de ácido sulfúrico sob agitação discreta, até o pH que corresponde ao ponto de equivalência da curva de titulação.

\section{Dureza Total}

A dureza total foi definida como a soma das concentrações de cálcio e magnésio, ambas expressas como carbonato de cálcio, em miligramas por litro. A dureza foi determinada pelo método titulométrico do EDTA. O ácido etilenodiaminotetracético e seus sais sódicos (EDTA) formaram complexos quelados solúveis com certos cátions metálicos. Uma solução contendo íons de cálcio e magnésio, com uma pequena quantidade do indicador negro de eriocromo $\mathrm{T}$, em $\mathrm{pH}(10,0 \pm 0,1)$ tornou-se purpura. Titulando-se essa solução com EDTA, cálcio e magnésio foram quelados e uma viragem de cor purpura a azul indicou o ponto final.

\section{Cloreto}

O cloreto, por sua vez, foi verificado pelo método argentométrico, em $\mathrm{mg} / \mathrm{L}$ de $\mathrm{Cl}^{-}$, no qual, após a adição, para cada $10 \mathrm{ml}$ da amostra de água com $90 \mathrm{ml}$ de água destilada, de $1 \mathrm{ml}$ do indicador de cromato de potássio $\left(\mathrm{K}_{2} \mathrm{CrO}_{4}\right)$, cuja cor é amareloesverdeada, titula-se inicialmente com a solução padrão de nitrato de prata $\left(\mathrm{AgNO}_{3}\right)$ a $0,00141 \mathrm{Ne}$, em seguida, para tornar o precipitado colorido, repetiu-se o procedimento (a chamada prova em branco), dessa vez com $100 \mathrm{ml}$ de água destilada, 
onde acrescentou-se uma pitada de carbonato de cálcio $\left(\mathrm{CaCO}_{3}\right)$ para a titulação com o $\mathrm{AgNO}_{3}$.

\section{Cor Aparente}

A cor foi determinada pelo método nefelométrico de comparação óptica, utilizando-se o Fotocolorímetro digital Policontrol - Instrumentos Analíticos (Aquacolor FE IP 67).

\section{Condutividade Elétrica}

A condutividade elétrica corresponde a condução da eletricidade através das soluções iônicas e se dá à custa da migração de íons positivos e negativos, com a aplicação de um campo eletrostático. A condutância de uma solução iônica depende do número de íons presentes, da carga e da mobilidade dos íons. Foi determinada por meio do condutivímetro portátil da Lutron, modelo $\mathrm{CD}-$ 4303, com resultados expressos na escala de $\mu \mathrm{S} / \mathrm{cm}$ a uma temperatura de $25^{\circ} \mathrm{C}$.

Sólidos Totais, Sólidos Totais Voláteis e Sólidos Totais Fixos

Foi determinado pelo método gravimétrico, que baseia-se na diferença de peso. Dessa forma, a determinação das várias formas de sólidos prende-se a diferença entre o peso seco e úmido, em relação ao volume de amostra utilizado no ensaio.

Lavou-se previamente a cápsula de porcelana como maneira de retirar qualquer impureza para não afetar os resultados. Aqueceu por uma hora em uma estufa a uma temperatura variando entre $103-105^{\circ} \mathrm{C}$. Ao retirar, resfriou-se até a temperatura ambiente em um dessecador. Após atingir a temperatura, pesou-se a cápsula e se anotou o valor. Homogeneizou-se bem a amostra tendo o cuidado de eliminar previamente os possíveis interferentes. Mediu-se $100 \mathrm{~mL}$ da amostra, e transferiu para a cápsula. Novamente fezse o processo de Evaporação desta vez utilizando a amostra na estufa entre $103-105^{\circ} \mathrm{C}$ por uma hora. Após a evaporação, levou-se a cápsula para o dessecador e deixou-la esfriar. Em seguida pesou-se novamente a cápsula.

\section{Nitrito}

O nitrito é determinado pelo método espectrofotométrico através da formação de um corante azóico púrpura avermelhado, produzido a um $\mathrm{pH}$ entre 2,0 e 2,5, através da sulfanilamida diazotizada com N (1-naftil) - dihidrocloreto de etilenodiamina (NED dihidrocloreto). A faixa de aplicação do método espectrofotométrico é de 10 a $1000 \mu \mathrm{g} \mathrm{N}-\mathrm{NO}_{3}{ }^{-}$.

\section{Nitrato}

É determinado pelo método espectrofotométrico. Utiliza-se o salicilato de sódio e obtêm-se resultados, por meio dos resíduos da evaporação de certa alíquota da mostra sob análise, que reage em condições ácidas com o salicilato de sódio formando paranitrossalicilato de sódio, o qual na presença de tartarato de sódio e potássio, em meio alcalino, dá uma coloração amarelada proporcional a sua concentração.

\section{RESULTADOS E DISCUSSÃO}

Potencial hidrogeniônico, temperatura, cor aparente e condutividade 
Com relação ao $\mathrm{pH}$ encontrado para esse estudo, todas as amostras atenderam aos padrões estipulados, pois os valores variaram de 7,74 a 8,07 a uma temperatura média de $26,4^{\circ} \mathrm{C}$ (Tabela 1).

De acordo com a portaria de consolidação $\mathrm{N}^{\circ}$ 05/2017 do Ministério da Saúde, o pH é padrão de potabilidade, devendo as águas para consumo humano apresentarem valores entre 6,00 e 9,5 (BRASIL, 2017).

$\mathrm{O}$ pH é a medida do balanço ácido de uma solução, definida como o logaritmo negativo da concentração de íons de hidrogênio. A escala de pH varia de 0 a 14, sendo que os valores abaixo de 7 e próximos de zero indicam aumento de acidez, enquanto os valores de 7 a 14 indicam aumento da alcalinidade (CHAPMAN \& KIMSTACH, 1996). Os valores de $\mathrm{pH}$ estão relacionados a fatores naturais, como dissolução de rochas, absorção de gases atmosféricos, oxidação da matéria orgânica e fotossíntese, e a fatores antropogênicos pelo despejo de esgotos domésticos e industriais, devido à oxidação da matéria orgânica e à lavagem ácida de tanques, respectivamente (VON SPERLING, 2005; LOPES; MAGALHÃES JR., 2010).

Resultados semelhantes foram encontrados por Silva et al. (2018) que fizeram uma análise físico-química da água utilizada para consumo nas escolas municipais da zona urbana de Esperança/PB, encontrando uma variação de $\mathrm{pH}$ que variou de 6,97 a 7,35, e por Euba Neto et al. (2012) que encontraram um $\mathrm{pH}$ com valor médio de 6,90 ao avaliarem as características físicas e químicas das águas do Balneário Veneza na bacia hidrográfica do médio Itapecuru, MA.

A temperatura é o parâmetro que faz a medição da intensidade de calor, refletindo o grau de aquecimento das águas e da radiação solar, e depende de fatores como clima, composição geológica, condutividade elétrica das rochas, dentre outras (MATIC et al., 2013). Os teores médios da temperatura neste estudo variaram de 25,6 a $27{ }^{\circ} \mathrm{C}$ (Tabela 1).

De acordo com Dezuane (1997), a temperatura é diretamente proporcional à velocidade das reações químicas, à solubilidade das substâncias, à concentração de oxigênio dissolvido, ao metabolismo dos organismos presentes no ambiente aquático, a formação de subprodutos da desinfecção, ao recrudescimento microbiológico e à taxa de corrosão nas tubulações integrantes dos sistemas de abastecimento.

Com relação a cor aparente, todas as amostras apresentaram um valor bem elevado, que variaram de 27,3 a 47,1 (Tabela 1). A portaria de consolidação № 05/2017 do Ministério da Saúde estabelece para cor aparente o Valor Máximo Permitido de 15 (quinze) uH como padrão de aceitação para consumo humano.

Segundo Richtter e Azevedo Netto (2002), a água pura é virtualmente ausente de cor. A presença de substâncias dissolvidas ou em suspensão altera a cor da água, dependendo da quantidade e da natureza do material presente. Normalmente, a cor na água é devida aos ácidos húmicos, fúlvicos e tanino, originados de decomposição de vegetais e, assim, não apresenta risco algum para a saúde. Porém, quando de origem industrial, pode ou não apresentar toxicidade (SPERLING, 1996; SILVA et al. 2017a). Resultados contraditórios foram encontrados por Silva et al. (2018) que observaram que todas as amostras atenderam ao padrão vigente, com exceção da amostra 6, que apresentou um valor de $20 \mathrm{uH}$, quando avaliaram alguns parâmetros físico-químicos da água utilizada para consumo nas escolas 
municipais da zona urbana de Esperança/PB e por Scuracchio (2010) que observou que todas as amostras atenderam ao padrão vigente, apresentando valores de cor abaixo de $15 \mathrm{uH}$, ao verificarem a qualidade microbiológica e físico-química da água que abastece as escolas de ensino fundamental e creches municipais da cidade de São Carlos-SP.

Mantovani et al. (2012), ao fazerem um levantamento pluviométrico e qualidade microbiológica e físico-química da água da chuva na cidade de Maringá, observaram um valor de cor aparente de $27 \mathrm{uH}$ encontrado para o telhado de fibrocimento. Jaques (2005) ao estudar telhados de fibrocimento e cerâmica encontrou resultados variados, 15 a $180 \mathrm{uH}$ no fibrocimento e para cerâmica de 15 a 75 uH.

A condutividade elétrica das águas resultou numa média de $380,6 \mu \mathrm{S} / \mathrm{Cm}$ a uma temperatura média de 26,4 ${ }^{\circ} \mathrm{C}$ (Tabela 1). Resultados contraditórios foram encontrados por Silva et al. (2017b), que observaram uma condutividade elétrica média de 232,3 $\mu \mathrm{S} / \mathrm{Cm}$ a temperatura média de 27,4 ${ }^{\circ} \mathrm{C}$, ao avaliarem parâmetros físico-químicos da água utilizada para consumo nas escolas municipais da zona urbana de Esperança/PB, e por Stein et al. (2012) que observaram uma condutividade elétrica média de 71,7 $\mu \mathrm{S} / \mathrm{cm}$ das águas do Aquífero Barreiras no setor sul de Natal e norte de Parnamirim, Rio Grande do Norte, Brasil.

De acordo com Libânio (2010), águas naturais apresentam usualmente condutividade elétrica inferior a $100 \mu \mathrm{S} / \mathrm{cm}$, podendo atingir $1000 \mu \mathrm{S} / \mathrm{cm}$ em corpos d'água receptores de elevadas cargas de efluentes domésticos e industriais.

Tabela 1. Valores de $\mathrm{pH}$, temperatura, cor aparente e condutividade das amostras de água coletadas nos bebedouros das escolas municipais de Esperança/PB ${ }^{1}$.

\begin{tabular}{ccccc}
\hline mostras & $\mathbf{p H}$ & mperatura $\left({ }^{\circ} \mathbf{C}\right)$ & aparente $(\mathbf{u H})^{\mathbf{2}}$ & $\begin{array}{c}\text { ondutividade } \\
(\boldsymbol{\mu S} / \mathbf{c m})\end{array}$ \\
\hline $\mathbf{1}$ & 7,74 & 25,6 & 36,1 & 423 \\
$\mathbf{2}$ & 7,96 & 26,6 & 27,3 & 509 \\
$\mathbf{3}$ & 8,07 & 26,4 & 45,1 & 424 \\
$\mathbf{4}$ & 7,96 & 27,0 & 47,1 & 433 \\
$\mathbf{5}$ & 7,90 & 26,5 & 25,5 & 114 \\
\hline Iédias & 7,92 & 26,4 & 36,2 & 380,6 \\
\hline VMP $^{3}$ & $6,0-9,5$ & $\mathrm{NR}^{4}$ & 15 & $\mathrm{NR}^{4}$
\end{tabular}

${ }^{1}$ Seguindo portaria de consolidação $\mathrm{N}^{\mathrm{0}}$ 05/2017 do Ministério da Saúde; ${ }^{2} \mathrm{uH}$ - Unidade Hazen; ${ }^{3} \mathrm{VMP}-$ Valor Máximo Permitido; ${ }^{4} \mathrm{NR}$ - Nenhuma Recomendação.

\section{Alcalinidade total} média de 79,18 mg/L de $\mathrm{CaCO}_{3}$, isso devido a presença de bicarbonatos (Tabela 2). 
A alcalinidade é a medida da capacidade que a água tem de neutralizar ácidos, isto é, a quantidade de substâncias na água que atuam como tampão (CLESCERI et al, 1998). Os compostos responsáveis pela alcalinidade total são sais que contém carbonatos $\left(\mathrm{CO}_{3}^{-2}\right)$, bicarbonatos $\left(\mathrm{HCO}_{3}^{-}\right)$, hidróxidos $\left(\mathrm{OH}^{-}\right)$e, secundariamente, aos íons hidróxidos, como cálcio e magnésio, silicatos, boratos, fosfatos e amônia. Em águas naturais, as medidas de $\mathrm{pH}$ e alcalinidade têm grande importância para o estudo de produtividade biológica, pois condicionam basicamente os demais processos físico-químicos em um corpo d'água, afetando a atividade biológica dos organismos aquáticos. Em águas de abastecimento e águas residuárias, as medidas de alcalinidade são utilizadas na interpretação e no controle de processos de tratamento (PARRON et al., 2011).

Silva et al. (2018) observaram um alcalinidade de $27,3 \mathrm{mg} / \mathrm{L}$ de $\mathrm{CaCO}_{3}$, ao analisarem os padrões físico-químicos da água utilizada pra consumo nas escolas municipais da zona urbana de Esperança/PB. Euba Neto et al. (2012), ao estudarem as características físicas, químicas e microbiológicas das águas da bacia hidrográfica do rio Itapecuru, em especial do Balneário Público Veneza em Caxias, Maranhão, observaram uma alcalinidade que variou de 253,47 a 256,70. Enquanto que, Pereira et al. (2010) observaram uma alcalinidade total média de 21,72 mg/L de $\mathrm{CaCO}_{3}$, ao avaliarem as condições de potabilidade da água consumida pela população de Abaetetuba, PA.

\section{Dureza total}

A dureza da água é expressa em $\mathrm{mg} / \mathrm{L}$ de equivalente em carbonato de cálcio $\left(\mathrm{CaCO}_{3}\right)$ e pode ser classificada em mole ou branda: $<50 \mathrm{mg} / \mathrm{L}$ de
$\mathrm{CaCO}_{3}$; dureza moderada: entre $50 \mathrm{mg} / \mathrm{L} \mathrm{e} 150 \mathrm{mg} / \mathrm{L}$ de $\mathrm{CaCO}_{3}$; dura: entre $150 \mathrm{mg} / \mathrm{L}$ e $300 \mathrm{mg} / \mathrm{L}$ de $\mathrm{CaCO}_{3}$; e muito dura: $>300 \mathrm{mg} / \mathrm{L}$ de $\mathrm{CaCO}_{3}$ (BRASIL, 2014).

De acordo com essa classificação, convém ressaltar que as referidas amostras estão dentro dos padrões de potabilidade brasileiro, americano e da Organização Mundial de Saúde (OMS), que estabelecem o limite de $500 \mathrm{mg} / \mathrm{L} \mathrm{CaCO}_{3}$, idêntico ao adotado no Canadá (HEALTH CANADA, 2004). Baseando-se na classificação citada anteriormente, as amostras 1, 2, 3, 4 e 5 apresentaram dureza mole ou branda, pois os resultados variaram de 18,8 a 46,3 $\mathrm{mg} / \mathrm{L}$ de $\mathrm{CaCO}_{3}$ (Tabela 2).

Silva et al. (2017b), ao analisarem os parâmetros físico-químicos da água utilizada para o consumo nas escolas municipais da zona urbana de Esperança/PB, observaram que as amostras apresentaram uma dureza moderada, e apenas a 82 amostra 2 apresentou água do tipo dura. Pereira et al. (2010) observaram uma dureza moderada de 64,40 $\mathrm{mg} / \mathrm{L}$ de $\mathrm{CaCO}_{3}$, ao avaliarem as condições de potabilidade da água consumida pela população de Abaetetuba, PA.

\section{Cloreto}

Verificou-se que o teor de cloreto foi em média de 57,26 mg/L de $\mathrm{Cl}^{-}$(Tabela 2), estando dentro dos padrões permitidos pela portaria de consolidação $\mathrm{N}^{\circ}$ 05/2017 do Ministério da Saúde que estabelece um teor de $250 \mathrm{mg} / \mathrm{L}$ de $\mathrm{Cl}^{-}$como valor máximo permitido para água potável.

Resultados semelhantes foram encontrados por Silva et al. (2018) que verificaram um teor médio de 119,63 mg/L de $\mathrm{Cl}^{-}$, Euba Neto et al. (2012) que observaram valores que variaram de 9,83 a 10,15 $\mathrm{mg} / \mathrm{L}$ ao estudarem as características físicas, 
químicas e microbiológicas das águas da bacia hidrográfica do rio Itapecuru, em especial do Balneário Público Veneza em Caxias, Maranhão e por Casali (2008) que realizaram um diagnóstico da qualidade da água destinada ao consumo humano das escolas e comunidades rurais da Região Central do Rio Grande do Sul, e observou que o nível de cloreto das águas variou de 0,2 a 16,2 mg/L, sendo encontrado os maiores valores sempre em águas subterrâneas.

Os cloretos, geralmente, provêm da dissolução de minerais ou da intrusão de águas do mar, e ainda podem advir dos esgotos domésticos ou industriais. Altas concentrações do íon cloreto na água podem ocasionar restrições ao seu uso pelo sabor que confere à mesma e pelo efeito laxativo que causam naqueles indivíduos que estavam acostumados a baixas concentrações. Os métodos convencionais para o tratamento da água não removem o íon cloreto, podendo ser removidos por osmose reversa e eletrodiálise (BRASIL, 2014).

\section{Nitrito e Nitrato}

Com relação ao nitrito, as amostras apresentaram valores menor que 1 , com média de 4,62 $\times 10^{-3}$ (Tabela 2), corroborando com a portaria de consolidação No 05/2017 do Ministério da Saúde que preconiza um Valor Máximo Permitido (VMP) igual a 1.

O nitrito é um estado de oxidação intermediário de nitrogênio, e ocorre tanto pela oxidação do amônio, como pela redução do nitrato. Ambos os processos (oxidação e redução) ocorrem em estações de tratamento de esgoto, em sistemas de distribuição de água e em águas naturais. Raramente o nitrito é encontrado em águas potáveis em níveis superiores a $0,1 \mathrm{mg} \mathrm{L}^{-1}$. $\mathrm{O}$ valor máximo permitido de nitrito em água potável é de $1,0 \mathrm{mg}$ de $\mathrm{NO}_{2}$ (BRASIL, 2011).

O nitrito, quando presente na água de consumo humano, tem um efeito mais rápido e pronunciado do que o nitrato. Se o nitrito for ingerido diretamente, pode ocasionar metemoglobinemia independente da faixa etária do consumidor (BATALHA; PARLATORE, 1993).

Resultados semelhantes foram encontrados por Fonseca (2017) que determinou o índice de nitrato, nitrito e nitrogênio amoniacal na água da lagoa de Extremoz/RN.

Com relação ao nitrato, verificou-se valores que variaram de 0,15 a $1,03 \mathrm{mg} / \mathrm{L}$, estando, portanto, de acordo com a portaria de consolidação $N^{\circ}$ 05/2017 do Ministério da Saúde que estabelece um valor máximo permitido de $10 \mathrm{mg} / \mathrm{L}$ (Tabela 2).

O nitrato é um dos íons mais encontrados em águas naturais, geralmente ocorrendo em baixos teores nas águas superficiais, mas podendo atingir altas concentrações em águas profundas (APHA, 1992). O seu consumo através das águas de abastecimento está associado a dois efeitos adversos à saúde: a indução à metemoglobinemia, especialmente em crianças, e a formação potencial de nitrosaminas e nitrosamidas carcinogênicas (MATO, 1996; NISHIHARA, 1998).

De acordo com Baird (2002), o excesso de nitrato na água potável pode levar a um aumento na incidência de câncer de estômago em seres humanos, uma vez que parte desses íons pode ser convertida em nitrito no estômago.

Resultados semelhantes foram encontrados por Kindlein (2010) que determinou o teor de nitratos e nitritos na água de abastecimento do município de Nova Santa Rita e por Fonseca (2017) que 
determinou o índice de nitrato, nitrito e nitrogênio

amoniacal na água da lagoa de Extremoz/RN.

Tabela 2. Valores de alcalinidade total, dureza total, cloreto, nitrito e nitrato das amostras de água coletadas nos bebedouros das escolas municipais de Esperança/PB ${ }^{1}$.

\begin{tabular}{|c|c|c|c|c|c|}
\hline 10stras & $\begin{array}{l}\text { lidade total }(\mathrm{mg} / \mathrm{L} \\
\left.\text { de } \mathrm{CaCO}_{3}\right)\end{array}$ & $\begin{array}{l}\text { ureza total } \\
\left.\mathrm{L} \text { de } \mathrm{CaCO}_{3}\right)\end{array}$ & $\begin{array}{l}\text { oreto } \\
\text { ag.L) }\end{array}$ & $\begin{array}{l}\text { Nitrito } \\
(\mathrm{mg} / \mathrm{L})\end{array}$ & $\begin{array}{l}\text { rato } \\
\text { g/L) }\end{array}$ \\
\hline 1 & 106,22 & 42,5 & 53,7 & $2,78 \times 10^{-3}$ &, 28 \\
\hline 2 & 85,70 & 46,3 & 78,8 & $2,14 \times 10^{-3}$ & ,46 \\
\hline 3 & 98,39 & 33,8 & 71,0 & $1,68 \times 10^{-3}$ &, 30 \\
\hline 4 & 76,81 & 32,5 & 73,4 & $7,45 \times 10^{3}$ &, 15 \\
\hline 5 & 28,78 & 18,8 & 9,4 & $5,07 \times 10^{-3}$ & ,03 \\
\hline Tédias & 79,18 & 34,78 & 7,26 &, $62 \times 10^{-3}$ &, 44 \\
\hline $\mathbf{M P}^{2}$ & $\mathrm{NR}^{3}$ & 500 & 250 & 1 & 10 \\
\hline
\end{tabular}

${ }^{1}$ Seguindo portaria de consolidação No $05 / 2017$ do Ministério da Saúde; ${ }^{2}$ VMP - Valor Máximo Permitido; ${ }^{3}$ Nenhuma Recomendação.

\section{Turbidez}

De acordo com as análises realizadas, as amostras apresentaram valores para turbidez que variaram de 0 a 0,33 (Tabela 3), corroborando com a portaria de consolidação No 05/2017 do Ministério da Saúde que preconiza um Valor Máximo Permitido (VMP) igual a 5 .

O alto nível de turbidez está intimamente relacionado à existência de matérias orgânicas e argilas suspensas na água, em que, a agregação destes componentes dá origem a coloides que interferem na penetração da luz (APHA, 1995; FERREIRA et al., 2015). Outros parâmetros, como por exemplo, o tamanho e a geometria das partículas que podem interferir na coloração e dispersão da luz na água, presença de algas, plâncton, zinco, ferro, manganês e até mesmo areia, sendo que, para comprovar o alto índice de turbidez é necessário realizar testes quantitativos para liberar a água para o consumo humano (ROBERTO et al., 2017).

A turbidez natural das águas superficiais está geralmente compreendida na faixa de 3 a $500 \mathrm{uT}$, e inferior a 1,0 uT para águas subterrâneas. Em lagos e represas, onde a velocidade de escoamento da água é menor, a turbidez tende a ser bastante baixa, com muita frequência inferior a 10 uT. Além da ocorrência de origem natural, a turbidez da água pode também ser causada por lançamentos de esgotos domésticos ou industriais (LIBÂNIO, 2010).

Alves et al (2008), em seu trabalho de avaliação da qualidade da água da bacia do rio Pirapó Maringá, Estado do Paraná, por meio de parâmetros físicos, químicos e microbiológicos, encontrou resultados semelhantes aos da presente pesquisa, em que a concentração de turbidez, nos pontos estudados, variou de 10 a 180 NTU/100 mL, durante o período trabalhado. Siqueira et al. (2012), ao avaliarem a qualidade da água do rio Parauapebas, 
encontraram valores de turbidez dentro dos padrões da legislação, que oscilou em consequência do material em suspensão devido à entrada de materiais carregados para o interior do rio por meio da lixiviação. A mesma situação foi encontrada por Queiroz et al., (2010) em seu trabalho sobre "Influência do uso do solo na qualidade da água de uma microbacia hidrográfica rural", realizado no município de Cascavel-PR.

\section{Sólidos Totais, Sólidos Totais Dissolvidos e Sólidos Totais Voláteis}

Com relação aos Sólidos Totais Dissolvidos, Sólidos Totais Voláteis e Sólidos Totais Fixos, as amostras provenientes dos bebedouros das escolas apresentaram valores que variaram de 94 a $302 \mathrm{mg}$ $\mathrm{L}^{-1}$, de 4 a $258 \mathrm{mg} \mathrm{L}^{-1}$ e 4 a $280 \mathrm{mg} \mathrm{L}^{-1}$, respectivamente (Tabela 3 ).

Sólidos totais dissolvidos são constituídos por partículas de diâmetro inferior a $10^{-3} \mu \mathrm{m}$ e que permanecem em solução mesmo após a filtração. A entrada de sólidos na água pode ocorrer de forma natural (processos erosivos, organismos e detritos orgânicos) ou antropogênica (lançamento de lixo e esgotos). O padrão de potabilidade refere-se apenas aos sólidos totais dissolvidos (limite: $1000 \mathrm{mg} \mathrm{L}^{-1}$ ), já que esta parcela reflete a influência de lançamento de esgotos, além de afetar a qualidade organoléptica da água (BRASIL, 2014).

Os sólidos totais dissolvidos (STD) estão relacionados diretamente com a condutividade elétrica (Araújo; Oliveira, 2013; Esteves, 1998, 2011; Tundisie e Matsumura Tundisi, 2008) e é usada em laboratório de rotina como medida da salinidade da água e/ ou dos efeitos causados por alguma atividade antrópica que afete um corpo d'água (VAN NIEKERK et al., 2014). Os STD, ao serem relacionados com a condutividade elétrica e quando não podem ser medidos, é usado um fator de conversão como no estudo realizado por Franciskovic-Bilinski et al. (2013) que multiplicou por 0,67 e desta forma calculou os STD das nascentes que estudaram.

Piratoba et al. (2017) encontraram teores médios de STD com valores de 16,28 a $27,05 \mathrm{mg} \mathrm{L}^{-1}$ para o período menos chuvoso e de 10,38 a $13,35 \mathrm{mg} \mathrm{L}^{-1}$ no período chuvoso, quando realizaram a caracterização de parâmetros de qualidade da água na área portuária de Barcarena, PA, Brasil. Em um estudo de Barreto et al. (2014), foram medidos os teores de STD e avaliada a relação entre a vazão e a qualidade da água numa seção do Rio Catolé Grande-BA, onde observou-se um aumento dos STD ao aumentar a vazão do rio.

Tavares (2009) encontrou resultados inferiores ao Valor Máximo Permitido (VMP), ocorrendo grande variação desse parâmetro entre 46 e $526 \mathrm{mg} / \mathrm{L}$ associado a origem da água. $\mathrm{O}$ comportamento ao longo dos meses foi previsível, sendo semelhante ao de condutividade e de salinidade, uma vez que a fração fixa dos sólidos dissolvidos totais inclui os íons que contribuem com a salinidade da água (SAWYER et al. 1994). Os valores dos Sólidos Totais Dissolvidos tenderam a aumentar ao longo dos meses, no período de estiagem e decresceram em todas as cisternas no período chuvoso. Observou-se uma tendência na elevação dos valores desse parâmetro, nos meses em que as cisternas receberam carros-pipa e redução nas cisternas com água apenas de chuva. 
Tabela 3. Valores de turbidez, sólidos totais, totais voláteis e sólidos totais fixos das amostras de água coletadas nos bebedouros das escolas municipais de Esperança/PB ${ }^{1}$.

\begin{tabular}{ccccc}
\hline Imostras & $\begin{array}{c}\text { Irbidez } \\
(\mathbf{u T})\end{array}$ & $\begin{array}{c}\text { idos totais } \\
(\mathbf{m g . L})\end{array}$ & $\begin{array}{c}\text { dos totais voláteis } \\
(\mathbf{m g} . \mathbf{L})\end{array}$ & $\begin{array}{c}\text { idos totais fixos } \\
(\mathbf{m g} . \mathbf{L})\end{array}$ \\
\hline $\mathbf{1}$ & 0,00 & 292 & 90 & 202 \\
$\mathbf{2}$ & 0,00 & 218 & 4 & 214 \\
$\mathbf{3}$ & 0,05 & 290 & 10 & 280 \\
$\mathbf{4}$ & 0,33 & 302 & 258 & 44 \\
$\mathbf{5}$ & 0,00 & 94 & 90 & 4 \\
\hline Médias & 0,076 & 239,2 & 90,4 & 148,8 \\
\hline VMP $^{2}$ & 5 & $\mathrm{NR}^{3}$ & $\mathrm{NR}^{3}$ & $\mathrm{NR}^{3}$
\end{tabular}

${ }^{1}$ Seguindo portaria de consolidação $N^{0}$ 05/2017 do Ministério da Saúde; ${ }^{2}$ VMP - Valor Máximo Permitido; ${ }^{3}$ Nenhuma Recomendação.

\section{CONCLUSÃO}

Com base nos resultados obtidos e analisando a luz da Portaria de Consolidação Nº 5/2017 do Ministério da Saúde, as referidas amostras encontra-se dentro dos padrões exigidos para potabilidade, exceto para o parâmetro Cor Aparente, que se encontra acima do valor máximo permitido $(15 \mathrm{uH})$.

\section{REFERÊNCIAS}

ALVES, S. G. S.; ATAIDE, C. D. G.; SILVA, J. X. Análise microbiológica de coliformes totais e termotolerantes em água de bebedouros de um parque público de Brasília, Distrito Federal. Rev. Cient. Sena Aires, v. 7, n. 1, p. 12-17, 2018.

ALVES, E. C.; SILVA, C. F.; COSSICH, E. S.; TAVARES, C. R. G.; FILHO, E. E. S.; CARNIEL, A. Avaliação da qualidade da água da bacia do Rio Pirapó - Maringá, Estado do Paraná, por meio de parâmetros físicos, químicos e microbiológicos. Rev. Acta Sci. Technol, v. 30, n. 1, p. 39-48, 2008.
APHA, AMERICAN PUBLIC HEALTH ASSOCIATION. Standard methods for the examination of water and wastewater. $17^{\mathrm{a}} \mathrm{ed}$. Washington, p.4-75/ 4-93, 1992.

APHA, AMERICAN PUBLIC HEALTH 86 ASSOCIATION. Standard methods for the examination of water and wastewater. $19^{\mathrm{a}} \mathrm{ed}$. New York: APHA, WWA, WPCR, p. 1268, 1995.

APHA, AMERICAN PUBLIC HEALTH ASSOCIATION. Standard Methods for the examination of water and wastewater. 22nd ed. Washington: American Public Health Association; 1360 pp, 2012.

ARAUJO, M. C.; OLIVEIRA, M. B M. Monitoramento da qualidade das águas de um riacho da Universidade Federal de Pernambuco, Brasil. Revista Ambiente \& Água, v. 8, n. 3, p. 247-257, 2013.

BAIRD, C. Química Ambiental. Porto Alegre: Bookman, 2002. 
BARRETO, L. V.; FRAGA, M. S.; BARROS, F. M.; ROCHA, F. A.; AMORIM, J. S.; DE CARVALHO, S. R. et al. Relação entre vazão e qualidade da água em uma seção de rio. Revista Ambiente \& Água, v. 9, p. 118-129, 2014.

Batalha, B. L.; PARlatore, A. C. Controle da qualidade da água para consumo humano: bases conceituais e operacionais. São Paulo: Cetesb, 1993.

BEAL, D. A.; FERREIRA, S. C.; RAUBER, D. Recursos Hídricos: Uso De Água Na Indústria - O Caso De Dois Vizinhos No Paraná-PR. III Congresso Nacional De Pesquisa Em Ciências Sociais Aplicadas- III CONAPE 2014; 2014; 01-03; Paraná, Brasil; p.1-20.

BRASIL. Resolução no 396 de 3 de abril de 2008. Brasília: Conselho Nacional do Meio Ambiente, 2008.

BRASIL. Portaria n ${ }^{0} 2914$ de 12 de dezembro de 2011 do Ministério da Saúde. Dispõe sobre os procedimentos de controle e de vigilância da qualidade da água para consumo humano e seu padrão de potabilidade.

BRASIL. Manual de Controle da Qualidade da Água para Técnicos que Trabalham em ETAS. Ministério da Saúde, Fundação Nacional de Saúde. Brasília: Funasa, 112 p., 2014.

BRASIL. Portaria de consolidação de $n^{0}$ de 28 de setembro de 2017 do Ministério da Saúde. Dispõe sobre os procedimentos de controle e de vigilância da qualidade da água para consumo humano e seu padrão de potabilidade.

CASALI, C. A. Qualidade da água para consumo humano ofertada em escolas e comunidades rurais da região central do Rio Grande do Sul.
Universidade Federal de Santa Maria, Dissertação de Mestrado, 173 p., 2008.

CHAPMAN, D.; KIMSTACH, V. Selection of water quality variables. In: CHAPMAN, D. (Ed.). Water quality assessments - a guide to use of biota, sediments and water in environmental monitoring. 2.ed. London: UNESCO/ WHO/UNEP, p.74-133, 1996.

CLESCERI, L. S.; GREENBERG, A. E.; EATON, A. D. Standard methods for the examination of water and wastewater. 20 th. ed. Washington, DC: American Public Health Association; American Water Works Association; Water Environment Federation, 1325p., 1998.

DEZUANE, J. Chemical Parameters - Inorganics. In: Drinking Water Quality, 2nd Ed., New York: John Wiley \& Sons, p. 575, 1997.

ESTEVES, F. Fundamentos de limnologia, Rio de Janeiro: Interciência, 601 p., 1998.

ESTEVES, F. Fundamentos de limnologia. $3^{\mathrm{a}}$ ed. Rio de Janeiro: Interciência, 826 p., 2011.

EUBA NETO, M.; SILVA, W. O.; RAMEIRO, F. C.; NASCIMENTO, E. S.; ALVES, A. S. Análises Físicas, Químicas e Microbiológicas das Águas do Balneário Veneza na Bacia Hidrográfica do Médio Itapecuru, MA. Arquivos do Instituto Biológico, v. 79, n. 3, p. 397-403, 2012.

FERREIRA, A. C.; ROCHA, L. C.; FIGUEIREDO, M. do A. Análise do índice de qualidade de água na bacia do Córrego do Rio Acima, São João DelRei/MG. Revista Nacional de Gerenciamento de Cidades, v. 03, n. 15, p. 94-105, 2015.

FONSECA, A. L. Determinação do índice de nitrato, nitrito e nitrogênio amoniacal na água da lagoa de Extremoz/RN. Universidade Federal do Rio Grande do Norte. Trabalho de Conclusão de Curso, 47 p., 2017. 
FRANCISKOVIC-BILINSKI, S.; CUCULIC, V.; BILINSKI, H.; HAUSLER, H.; STADLER, P. Geochemical and stable isotopic variability within two rivers rising under the same mountain, but belonging to two distant watersheds. Chemie der Erde-Geochemistry, v. 73, p. 293-308, 2013.

HEALTH CANADA. Guidelines for Canadian drinking water quality. 2004. Disponível em:<www.hc-sc.gc.ca/ewh-semt/pubs/watereau/enteric-enterovirus/index-eng.php>. Acesso em: 21 nov. 2018.

IBGE. 2018. Cidades. Disponível em: < https://cidades.ibge.gov.br/brasil/pb/esperanca/pano rama>. Acesso em: 13 set. 2018.

JAQUES, R. C. Qualidade da água de chuva no município de Florianópolis e sua potencialidade para aproveitamento em edificações. Dissertação de Mestrado. Programa de Pós-Graduação em Engenharia Sanitária e Ambiental. Universidade Federal de Santa Catarina, Blumenau, 2005.

KINDLEIN, C. P. Determinaçãa do teor de nitratos e nitritos na água de abastecimento do município de Nova Santa Rita. Trabalho de Conclusão de Curso, Unilasalle (Centro Universitário La Sale), 68 p., Canos, 2010.

LIBÂNIO, M. Fundamentos de Qualidade e Tratamento de Água. 3. ed. Campinas: Editora Átomo, 2010. 494p.

LOPES, F. W. A.; MAGALHÃES JR. Influência das condições naturais de $\mathrm{pH}$ sobre o índice de qualidade das água (IQA) na Bacia do Ribeirão de Carrancas.

Revista Brasileira de Recursos Hídricos, Belo Horizonte, v. 6, N. 2, p. 134-147, 2010.

MANTOVANI, D.; CORAZZA, M. L.; CARDOZO FILHO, L.; COSTA, S. C.; SCHMIDT, C. A. P. Levantamento Pluviométrico e Qualidade Microbiológica e Físico-química da água da chuva na cidade de Maringá, Paraná. Revista Tecnológica, v. 21, p. 93-102, 2012.

MATIC, N.; MIKLAVCIC, I.; MALDINI, K.; DAMIR, T.; CUCULIC, V.; CARDELLINI, C.; FRANCISKOVIC-BILINSKI, S. Geochemical and isotopic characteristics of karstic springs in coastal mountains (Southern Croatia). Journal of Geochemical Exploration, n. 132, p. 90-110, 2013. MATO, A. P. Determinação de nitratos, nitritos e prováveis fontes de contaminação em águas de poços e sua influência na metemoglobinemia infantil. Dissertação de Mestrado - Curso de PósGraduação em Saneamento Ambiental, Universidade Mackenzie. São Paulo, 1996.

NISHIHARA, J. A. L. Presença de compostos de nitrogênio em águas de poços. Revista de Saúde Pública, v. 32, n. 2, p. 160-165, 1998.

PARRON, L. M.; MUNIZ, D. H. F.; PEREIRA, C. M. Manual de procedimentos de amostragem e análise físico-química de água. Empresa Brasileira de Pesquisa Agropecuária. Colombo, PR, Documentos 232/Embrapa Florestas, 69 p., 2011.

PEREIRA, S. F. P.; COSTA, A. C.; CARDOSO, E. S. C.; CORRÊA, M. S. S.; ALVES, D. T. V.; MIRANDA, R. G.; OLIVEIRA, G. R. F. Condições de potabilidade da água consumida pela população de Abaetetuba-Pará. Revista de Estudos Ambientais, v. 12, n. 1, p. 50-62, 2010.

PINTO-COELHO, R. M.; HAVENS, K. Gestão de Recursos Hídricos em Tempos de Crise. Porto Alegre: Artmed. 228p. 2016.

PIRATOBA, A. R. A.; RIBEIRO, H. M. C.; MORALES, G. P.; GONÇALVES, W. G. Caracterização de parâmetros de qualidade da água na área portuária de Barcarena, PA, Brasil. Revista Ambiente \& Água, v. 12 n. 3, 2017. 
PORTO, M. A. L.; OLIVEIRA, A. M.; FAI, A. E. C.; STAMFORD, T. L. M. Coliformes em água de abastecimento de lojas fast food da Região Metropolitana de Recife (PE, Brasil). Ciênc. saúde coletiva, v. 16, n. 5, p. 2653-2658, 2011.

QUEIROZ, M. M. F.; IOST, C.; GOMES, S. D.; VILAS BOAS, M. A. Influência do uso do solo na qualidade da água de uma microbacia hidrográfica rural. Rev. Verde de Agroecologia e desenvolvimento sustentável. V. 5, n. 4, p. 200$210,2010$.

RICHTER, C. A., AZEVEDO NETTO J. M. Tratamento de água: tecnologia atualizada. São Paulo: Edgard Blucher, 2002. 332p.

RIBEIRO, L. G. G.; ROLIM, N. D. Planeta água de quem e para quem: uma análise da água doce como direito fundamental e sua valoração mercadológica. RDAS, v. 7, n. 1, p. 7-33, 2017.

ROBERTO, M. C.; GUIMARÃes, A. P. M.; RIBEIRO, J. L.; CARVALHO, A. V.; NERES, J. C. I.; CERQUEIRA, F. B. Avaliação do pH, turbidez e análise microbiológica da água do córrego Guará Velho em Guaraí, Estado do Tocantins. Revista Desafios, v. 4, n. 4, p. 3-14, 2017.

SAWYER, C. N.; McCARTY, P. L.; PARKIN, G. F. Chemistry for environmental engineering. 4 ed. New York: McGraw-Hill, 1994.

SCURACCHIO, P. A. Qualidade da Água Utilizada para Consumo em Escolas no Município de São Carlos-SP. Dissertação (Mestrado). Araraquara, 57p., 2010.

SILVA, A. B; BRITO, J. M.; SILVA, R. A.; BRAZ, A. S.; SILVA FILHO, E. D. Parâmetros Físicoquímicos da água utilizada para consumo em poços artesianos na cidade de Remígio-PB. Águas Subterrâneas, v. 31, n. 2, p. 109-118, $2017 \mathrm{a}$.
SILVA, A. B; BRITO, J. M.; DUARTE, J. S.; BRAZ, A. S.; SILVA, R. A. Parâmetros físicoquímicos da água utilizada para consumo nas escolas municipais da zona urbana de Esperança/PB. Revista Brasileira de Gestão Ambiental, v. 11, n. 1, p. 36-41, 2017b.

SILVA, A. B; BRITO, J. M.; DUARTE, J. S.; BRAZ, A. S.; SILVA, R. A.; SILVA FILHO, E. D. Análise físico-química da água utilizada para consumo nas escolas municipais da zona urbana de Esperança/PB. Biota Amazônia, Macapá, v. 8, n. 3, p. 49-52, 2018.

SIQUEIRA, G.W.; APRILE, F.; MIGUÉIS, A.M. Diagnóstico da qualidade da água do rio Parauapebas (Pará - Brasil). Rev. Acta Amazônica. v. 42, n. 3, p. $413-422,2012$.

SPERLING, M. V. Introdução à qualidade das águas e do tratamento de esgotos. 2 ed. Minas Gerais: UFMG, 1996. 243p.

STEIN, P.; DINIZ FILHO, J. B.; LUCENA, L. R. F.; CABRAL, N. M. T. Qualidade das águas do aquífero Barreiras no setor sul de Natal e norte de Parnamirim, Rio Grande do Norte, Brasil. Revista Brasileira de Geociências, v. 42, p. 226-237, 2012. TAVARES, A. C. Aspectos Físicos, Químicos e Microbiológicos da Água Armazenada em Cisternas de Comunidades Rurais no Semi-árido Paraibano. Dissertação. PRODEMA, 169 p., 2009. TRINDADE, G. A.; SÁ-OLIVEIRA, J. C.; SILVA, E. S. Avaliação da qualidade da água em três escolas públicas da cidade de Macapá, Amapá. Biota Amazônia, v. 5, n. 1, p. 116-122, 2015.

TUNDISI, J. G.; MATSUMURA TUNDISI, T. Limnologia. São Paulo: Oficina de Textos, 632 p., 2008.

VAN NIEKERK, H.; SILBERBAUER, M. J.; MALULEKE, M. Geographical differences in the 
relationship between total dissolved solids and electrical conductivity in South African rivers. Water SA, v. 40, n. 1, p. 133-137, 2014.
VON SPERLING, M. Introdução à qualidade das águas e ao tratamento de esgotos. 3.ed. Belo Horizonte: UFMG/ Departamento de Engenharia Sanitária, 2005. v.1, 452p 